\title{
Laparoscopic jejunostomy for obstructing upper gastrointestinal malignancies
}

\author{
HIRONORI TSUJIMOTO, SHUICHI HIRAKI, RISA TAKAHATA, SHINSUKE NOMURA, NOZOMI ITO, \\ KYOHEI KANEMATSU, HIROYUKI HORIGUCHI, SUEFUMI AOSASA, JUNJI YAMAMOTO and KAZUO HASE
}

\author{
Department of Surgery, National Defense Medical College, Tokorozawa, Saitama 359-8513, Japan
}

Received April 9, 2015; Accepted June 11, 2015

DOI: $10.3892 / \mathrm{mco} .2015 .612$

\begin{abstract}
The aim of this study was to describe a minimally invasive laparoscopic jejunostomy (Lap-J) technique for obstruction due to upper gastrointestinal malignancies and evaluate the nutritional benefit of Lap-J during neoadjuvant chemotherapy (NAC) in cases with obstructing esophageal cancer. Under general anesthesia, the jejunum 20-30 cm distant from the Treitz ligament was pulled out through an extended umbilical laparoscopic incision and a jejunal tube was inserted to $30 \mathrm{~cm}$. The loop of bowel was gently returned to the abdomen and the feeding tube was drawn through the abdominal wall via the left lower incision. The jejunum was then laparoscopically sutured to the anterior abdominal wall. Lap-J was performed in 26 cases. The median operative time was $82 \mathrm{~min}$. The postoperative course was uneventful. Lap-J prior to NAC was not associated with a decrease in body weight or serum total protein during NAC, compared with patients who received NAC without Lap-J. This minimally invasive jejunostomy technique may be particularly useful in patients in whom endoscopic therapy is not feasible due to obstruction from upper gastrointestinal malignancies.
\end{abstract}

\section{Introduction}

Enteral nutrition is preferred in patients who are malnourished or undergoing cancer treatment and during the perioperative period (1-3). Safe and reliable methods for the placement of feeding tubes, such as percutaneous endoscopic gastrostomy (PEG) (4), laparoscopic gastrostomy (5) and nasogastric tube (NGT) feeding (6), have revolutionized nutritional therapy in such patients. However, NGT and PEG are not feasible in cases where tube or endoscopic therapy is not possible due to obstruction of the pharynx or esophagus; in addition, NGT compromises the patients' quality of life. Jejunostomy is often

Correspondence to: Dr Hironori Tsujimoto, Department of Surgery, National Defense Medical College, 3-2 Namiki, Tokorozawa, Saitama 359-8513, Japan

E-mail: tsujihi@ndmc.ac.jp

Key words: laparoscopic jejunostomy, minimally invasive surgery, esophageal cancer, enteral nutrition indicated in cases where gastrostomy is not feasible, including gastric and esophageal cancer, where gastric tube reconstruction is planned.

In this study, we describe a minimally invasive method of laparoscopic jejunostomy (Lap-J) for obstruction due to upper gastrointestinal malignancies. In addition, we evaluated the nutritional benefits of Lap-J during neoadjuvant chemotherapy (NAC) in cases of obstructing esophageal cancer.

\section{Patients and methods}

Patients. We conducted a non-randomized retrospective study of 26 patients who underwent Lap-J for obstruction due to esophageal or gastric cancer at the National Defense Medical College Hospital between January, 2008 and February, 2015. The indications for Lap-J included previous gastric or duodenal surgery, gastroparesis, high risk of aspiration and esophageal or gastric cancer where gastrostomy was technically impossible or contraindicated. The contraindications for Lap-J were unsuitability for general anesthesia and gastrointestinal disease. In order to evaluate the nutritional benefits of Lap-J during NAC, we compared nutritional parameters such as body weight, serum total protein, albumin, lymphocyte count and prognostic nutritional index (7) between patients who underwent Lap-J prior to NAC (Lap-J group, n=9) and those who received NAC without Lap-J (control group, $\mathrm{n}=56$ ).

Chemotherapy with cisplatin plus 5-fluorouracil (5-FU) was repeated twice every 3 weeks. A dose of $80 \mathrm{mg} / \mathrm{m}^{2}$ cisplatin was administered by intravenous drip infusion for $2 \mathrm{~h}$ on day 1; 5-FU was administered at a dose of $800 \mathrm{mg} / \mathrm{m}^{2}$ by continuous infusion on days 1-5.

Surgical procedure. Following induction of general anesthesia, the patient was placed in a supine position. The surgeon and laparoscopist stood on the right side of the patient and the first assistant on the left side. A camera port was inserted through a median umbilical incision. Next, a $12 \mathrm{mmHg}$ pneumoperitoneum was induced and 3 additional ports $(2$ ports with a diameter of $5 \mathrm{~mm}$ and 1 port with a diameter of $12 \mathrm{~mm}$ ) were inserted under laparoscopic imaging into the right upper, left lower and right lower quadrants, as shown in Fig. 1.

Following exploration of the peritoneal cavity, the jejunum 20-30 cm distant from the Treitz ligament was pulled out through the umbilical trocar incision, which was extended 


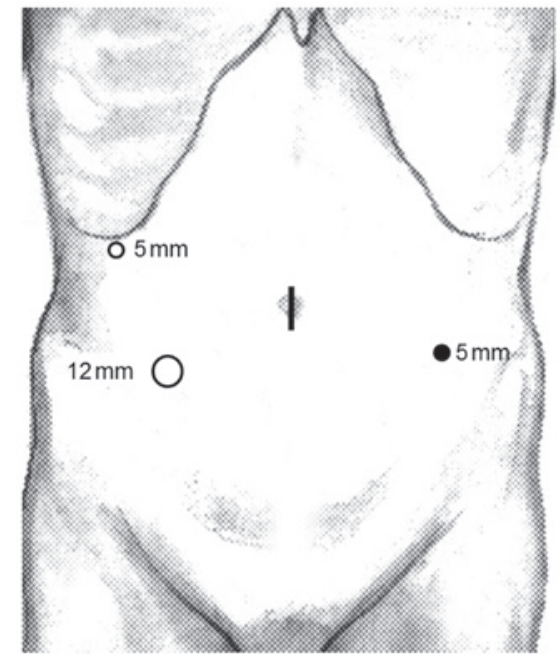

Figure 1. Port positioning. A camera port was inserted through a median umbilical incision and 3 additional ports (1 port with a diameter of $12 \mathrm{~mm}$ and 2 ports with a diameter of $5 \mathrm{~mm})$ were inserted into the right lower $(12 \mathrm{~mm})$, right upper $(5 \mathrm{~mm})$ and left lower $(5 \mathrm{~mm})$ quadrants under laparoscopic imaging. The left lower quadrant port was the intended jejunostomy site.

to $\sim 2 \mathrm{~cm}$ by enlarging the median fascia and skin incision before covering with an Alexis wound retractor (Applied Medical, Tokyo, Japan) (Fig. 2A). After a serosal suture (4-0 PDS; Ethicon, Tokyo, Japan) was placed, a trocar with a peel-away sheath (Covidien, Tokyo, Japan) was used to penetrate the subserosa for $\sim 8 \mathrm{~cm}$ prior to penetrating the jejunal lumen (Fig. 2B). The peel-away sheath was removed and the jejunal tube was inserted to $30 \mathrm{~cm}$. Intraluminal placement was confirmed by flushing with saline. The tube was held by a laparoscopic grasper inserted through the left lower trocar (Fig. 2C). The loop of bowel was gently returned to the abdomen and the feeding tube was drawn through the abdominal wall via the left lower incision. The jejunum was laparoscopically sutured to the anterior abdominal wall using 5 or 6 sutures (3-0 Monocryl; Ethicon) (Fig. 2D).

Statistical analysis. Data are expressed as means \pm standard deviation. Comparisons between the two groups were performed using the Wilcoxon signed-rank test. Data were analyzed using the MedCalc v9.0 statistical software package (MedCalc, Mariakerke, Belgium). A P-value of $<0.05$ was considered to indicate statistically significant differences.

\section{Results}

Short-term outcomes of Lap-J. We safely performed the Lap-J procedure in 26 patients with obstructing upper gastrointestinal malignancies (Table I). The primary indications were esophageal $(n=22)$ and gastric cancer $(n=4)$. The mean age was $69.4 \pm 6.0$ years (range, 48-79 years). All the patients had stage III or IV disease, except for 1 case of stage I gastric cancer. Nine esophageal cancer patients had NAC followed by surgery after Lap-J. The mean operative time was $81.6 \pm 29.6$ min (range, $35-155 \mathrm{~min}$ ). The mean estimated intraoperative blood loss was $1.2 \pm 0.4 \mathrm{ml}$ (range, $0-15 \mathrm{ml}$ ). All the patients were able to stand, walk and resume enteral nutrition on postoperative day 1, without complications. The mean postoperative hospital stay was
Table I. Demographic data of patients who underwent Lap-J.

\begin{tabular}{|c|c|}
\hline Variables & $\begin{array}{l}\text { No. of patients } \\
\qquad(n=26)\end{array}$ \\
\hline Age, years & $69.4 \pm 6.0(48-79)$ \\
\hline \multicolumn{2}{|l|}{ Gender } \\
\hline Male & 22 \\
\hline Female & 4 \\
\hline BMI, $\mathrm{kg} / \mathrm{m}^{2}$ & $19.3 \pm 2.9(14.6-24.0)$ \\
\hline \multicolumn{2}{|l|}{ Location } \\
\hline Esophageal cancer & 22 \\
\hline Gastric cancer & 4 \\
\hline \multicolumn{2}{|l|}{ Stage } \\
\hline I & 1 \\
\hline II & 0 \\
\hline III & 15 \\
\hline IV & 10 \\
\hline \multicolumn{2}{|l|}{ Type of treatment } \\
\hline Surgery & 2 \\
\hline Chemotherapy followed by surgery & 9 \\
\hline Chemoradiation therapy & 6 \\
\hline Chemotherapy & 4 \\
\hline Radiation therapy & 1 \\
\hline Best supportive care & 4 \\
\hline
\end{tabular}

Data are presented as absolute numbers or as mean \pm standard deviation (range). Lap-J, laparoscopic jejunostomy; BMI, body mass index.

Table II. Surgical outcomes of Lap-J.

\begin{tabular}{lc}
\hline Variables & No. \\
\hline Operative time, min & $81.6 \pm 29.6(35-155)$ \\
Blood loss, g & $0.9 \pm 2.9(0-15)$ \\
Start of enteral feeding, days & $1.2 \pm 0.4(1-2)$ \\
Start of subsequent therapy, days & $11.5 \pm 6.3(3-27)$ \\
Hospital stay following Lap-J, days & $21.6 \pm 18.3(1-84)$ \\
Complications & \\
Diarrhea & 3 \\
Obstruction of the tube & 2 \\
Leakage & 0 \\
Dislodgement & 0 \\
Perforation & 0 \\
Bowel necrosis & 0 \\
Bowel torsion & 0 \\
Herniation & 0 \\
\hline
\end{tabular}

Data are presented as absolute numbers or as mean \pm standard deviation (range) Lap-J, laparoscopic jejunostomy.

$21.6 \pm 18.3$ days (range, 1-84 days). The hospital stay was prolonged in 20 cases, the causes of which are listed in Table II. Subsequent therapy was initiated $11.5 \pm 6.3$ days (range, 3-27 days) after 
Table III. Nutritional data prior to and following NAC for esophageal cancer in patients who did and those who did not undergo Lap-J.

\begin{tabular}{|c|c|c|c|c|c|c|}
\hline \multirow[b]{2}{*}{ Variables } & \multicolumn{3}{|c|}{$\begin{array}{l}\text { With Lap-J } \\
\qquad(n=9)\end{array}$} & \multicolumn{3}{|c|}{$\begin{array}{l}\text { Without Lap-J } \\
\qquad(\mathrm{n}=56)\end{array}$} \\
\hline & Prior to NAC & Following NAC & P-value & Prior to NAC & Following NAC & P-value \\
\hline Body weight, kg & $47.3 \pm 8.2$ & $47.7 \pm 6.3$ & 0.6072 & $58.3 \pm 5.5$ & $56.4 \pm 4.8$ & 0.0020 \\
\hline Total protein, g/dl & $6.89 \pm 0.46$ & $6.90 \pm 0.46$ & 0.9291 & $6.61 \pm 0.53$ & $6.26 \pm 0.53$ & 0.0010 \\
\hline Albumin, g/dl & $3.78 \pm 0.15$ & $3.69 \pm 0.13$ & 0.4496 & $3.83 \pm 0.37$ & $3.72 \pm 0.47$ & 0.0815 \\
\hline Lymphocyte count, $/ \mu 1$ & $1,349.2 \pm 425.8$ & $1,962.7 \pm 783.4$ & 0.0873 & $1,539.8 \pm 500.5$ & $1,550.5 \pm 447.3$ & 0.8735 \\
\hline PNI & $38.4 \pm 4.3$ & $37.9 \pm 3.9$ & 0.6205 & $39.1 \pm 3.8$ & $38.0 \pm 4.7$ & 0.0837 \\
\hline
\end{tabular}

Data are presented as mean \pm standard deviation. NAC, neoadjuvant chemotherapy; Lap-J, laparoscopic jejunostomy; PNI, prognostic nutritional index.
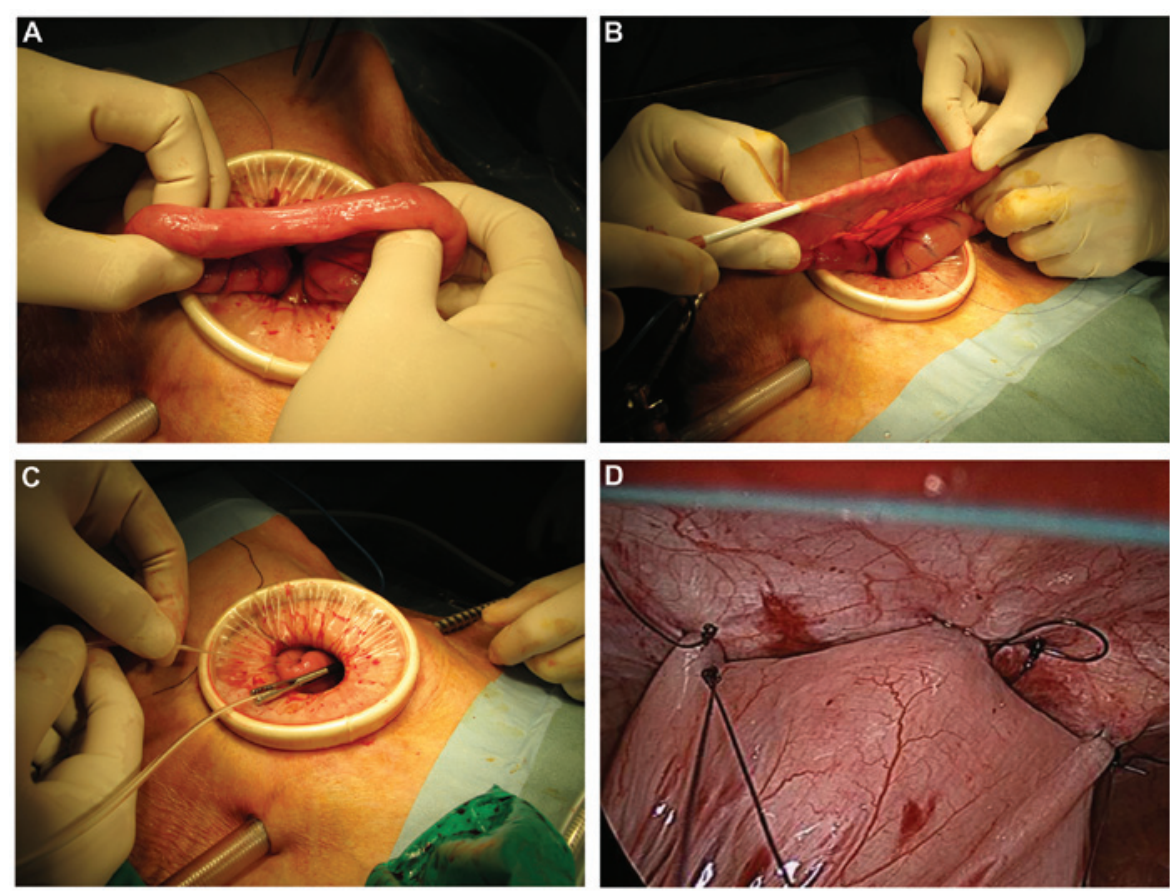

Figure 2. Surgical procedures in laparoscopic jejunostomy. (A) Following exploration of the peritoneal cavity, the jejunum $20-30 \mathrm{~cm}$ distant from the Treitz ligament was pulled out through the umbilical trocar incision. (B) After a serosal suture was placed, a trocar with a peel-away sheath was used to penetrate the subserosa for $\sim 8 \mathrm{~cm}$ prior to penetrating the jejunal lumen. (C) The peel-away sheath was removed and a jejunal tube was inserted to $30 \mathrm{~cm}$. The tube was held by a laparoscopic grasper inserted through the left lower trocar. The loop of bowel was gently returned to the abdomen and the feeding tube was drawn through the abdominal wall via the left lower incision. (D) The jejunum was laparoscopically sutured to the anterior abdominal wall with 5 or 6 sutures.

Lap-J, excluding cases receiving palliative care. Three cases developed diarrhea that improved with reduced feeding speed and 2 cases developed obstruction of the jejunostomy tube and tubes were exchanged using a guide wire. There was no Lap-J-related mortality.

Nutritional benefits of Lap-J during NAC for obstructing esophageal cancer. The nutritional parameters prior to and following NAC in the two groups are presented in Table III. Although there was a significant decrease in body weight and serum total protein following NAC in the control group, no such changes were observed in the Lap-J group. No change in serum albumin, lymphocyte count, or prognostic nutritional index following NAC was observed in either group.

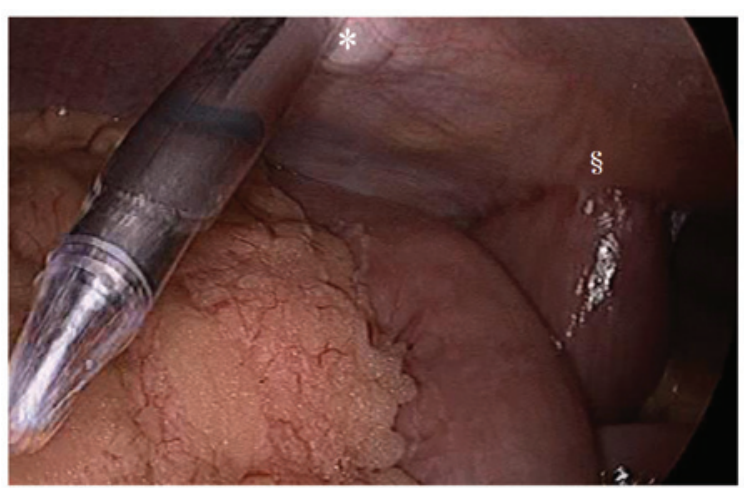

Figure 3. Laparoscopic view during esophagectomy following laparoscopic jejunostomy (Lap-J). §, jejunum sutured to the anterior abdominal wall for Lap-J; *, trocar in the left lower quadrant during esophagectomy. 


\section{Discussion}

In this study, we demonstrated a simple and safe technique for Lap-J with jejunopexy. There was no procedure-related mortality and enteral nutrition was resumed the following day in all the patients.

As laparoscopic feeding jejunostomy was first described in 1990 (8), several modified procedures for Lap-J have since been developed (9-12). Duh et al (13) described laparoscopy-assisted percutaneous placement of jejunostomy catheters using T-fasteners to retract and anchor the jejunum. This procedure is advantageous, as it does not require extension of the umbilical trocar incision or exposure of the jejunum. However, this procedure does not penetrate the subserosa for a sufficient length to avoid the use of the Witzel technique (14). Enterocutaneous fistula formation around the feeding tube is one of the most serious complications of jejunostomy. To avoid this complication, the techniques must involve affixation of the jejunum to the parietal peritoneum at the puncture site and employment of a subserous tunnel, as in our technique. Several studies have reported laparoscopy-guided techniques that exteriorize the proximal jejunum with the insertion of feeding tubes through an enterotomy and securing by extracorporeal fixation to the fascia with non-absorbable or absorbable stitches $(15,16)$.

Obstructing esophageal cancer with planned gastric tube reconstruction is a common indication for jejunostomy. In Japan, preoperative chemotherapy with cisplatin plus 5-FU is considered standard treatment for patients with stage II/III esophageal squamous cell carcinoma (17). We performed Lap-J in 9 patients with stage II/III esophageal cancer prior to NAC. No abdominal adhesions were observed in these patients and there were no complications or difficulties in laparoscopic gastric tube reconstruction and abdominal lymph node dissection (Fig. 3) (18). No increase in laparoscopic operative time was observed (Lap-J vs. control group, 285 vs. $292 \mathrm{~min}$, respectively). In addition, Lap-J prior to NAC was not associated with a decrease in body weight or serum total protein during NAC, compared with patients receiving NAC who did not undergo Lap-J. Thus, Lap-J prior to NAC may be useful in patients with obstructing esophageal cancer for whom gastric tube reconstruction is planned.

In conclusion, we described a minimally invasive jejunostomy technique that may be particularly useful for patients in whom endoscopic therapy is not feasible due to obstruction from upper gastrointestinal malignancies.

\section{References}

1. Braga M, Ljungqvist O, Soeters P, Fearon K, Weimann A and Bozzetti F; ESPEN: ESPEN guidelines on parenteral nutrition: Surgery. Clin Nutr 28: 378-386, 2009.

2. Aiko S, Kumano I, Yamanaka N, Tsujimoto H, Takahata R and Maehara T: Effects of an immuno-enhanced diet containing antioxidants in esophageal cancer surgery following neoadjuvant therapy. Dis Esophagus 25: 137-145, 2012.

3. Braga M, Gianotti L, Nespoli L, Radaelli G and DiCarlo V: Nutritional approach in malnourished surgical patients: A prospective randomized study. Arch Surg 137: 174-180, 2002.

4. Russell TR, Brotman M and Norris F: Percutaneous gastrostomy. A new simplified and cost-effective technique. Am J Surg 148: 132-137, 1984.

5. Tsujimoto H, Yaguchi Y, Kumano I, Matsumoto Y, Yoshida K and Hase K: Laparoscopy-assisted percutaneous gastrostomy tube placement along with laparoscopic gastropexy. Dig Surg 28: 163-166, 2011.

6. Nally DM, Kelly EG, Clarke M and Ridgway P: Nasogastric nutrition is efficacious in severe acute pancreatitis: A systematic review and meta-analysis. Br J Nutr 112: 1769-1778, 2014.

7. Okamura Y, Ashida R, Ito T, Sugiura T, Mori K and Uesaka K: Preoperative neutrophil to lymphocyte ratio and prognostic nutritional index predict overall survival after hepatectomy for hepatocellular carcinoma. World J Surg 39: 1501-1509, 2015.

8. O'Regan PJ and Scarrow GD: Laparoscopic jejunostomy. Endoscopy 22: 39-40, 1990.

9. Albrink MH, Foster J, Rosemurgy AS and Carey LC: Laparoscopic feeding jejunostomy: Also a simple technique. Surg Endosc 6: 259-260, 1992.

10. Allen JW, Ali A, Wo J, Bumpous JM and Cacchione RN: Totally laparoscopic feeding jejunostomy. Surg Endosc 16: 1802-1805, 2002.

11. Grondona P andreani SM, Barr N and Singh KK: Laparoscopic feeding jejunostomy technique as part of staging laparoscopy. Surg Laparosc Endosc Percutan Tech 15: 263-266, 2005.

12. Han-Geurts IJ, Lim A, Stijnen T and Bonjer HJ: Laparoscopic feeding jejunostomy: A systematic review. Surg Endosc 19: 951-957, 2005.

13. Duh QY, Senokozlieff-Englehart AL, Siperstein AE, et al: Prospective evaluation of the safety and efficacy of laparoscopic jejunostomy. West J Med 162: 117-122, 1995.

14. Pearce CB and Duncan HD: Enteral feeding. Nasogastric, nasojejunal, percutaneous endoscopic gastrostomy, or jejunostomy: Its indications and limitations. Postgrad Med J 78: 198-204, 2002.

15. Gedaly R, Briceño P, Ravelo R and Weisinger K: Laparoscopic jejunostomy with an 18-mm trocar. Surg Laparosc Endosc 7: 420-422, 1997.

16. Düzgün SA, Bozer M, Coskun A, et al: A simplified laparoscopic technique for enteral access in cancer patients. Hepatogastroenterology 49: 1002-1005, 2002.

17. Ando N, Kato H, Igaki H, et al: A randomized trial comparing postoperative adjuvant chemotherapy with cisplatin and 5-fluorouracil versus preoperative chemotherapy for localized advanced squamous cell carcinoma of the thoracic esophagus (JCOG9907). Ann Surg Oncol 19: 68-74, 2012.

18. Tsujimoto H, Ono S, Sugasawa H, et al: Gastric tube reconstruction by laparoscopy-assisted surgery attenuates postoperative systemic inflammatory response after esophagectomy for esophageal cancer. World J Surg 34: 2830-2836, 2010. 